\title{
Performance of domestic heat storage devices controlled by a smart grid
}

\author{
Joe Clarke, Jon Hand, Jae-min Kim, Aizaz Samuel and Katalin Svehla \\ ESRU, University of Strathclyde, United Kingdom
}

(J Power Eng rules: no more than 5000 words and 10 figures

Current draft: 5117 words (excl abstract \& refs), 9 figures)

\begin{abstract}
Distributed, small-scale energy storage has been identified as a means of improving the load factors in intermittent renewable generation and displacing the need for fossil-based backup. Domestic electric space and water heating equipment operating in a smart grid offer high density, controllable energy storage at low cost, allowing the network operator to shift demand by charging heaters to dispose of excess supply. This paper reports on the performance of such a system as deployed in Shetland: here, heaters are capable of responding to instructions from the grid to vary charging level at 15 minute intervals, as well as to occupant-set controls on power output. Performance is assessed from the viewpoint of both the grid operator - controllability, storage utilisation and overall demand - and of occupants - comfort, demand and cost. Improved insulation coupled with the capacity to deliver dynamic charge scheduling were found to overcome the drawbacks experienced with traditional storage heaters and make this work well for both.
\end{abstract}

\section{Keywords}

Load shifting, storage heating, domestic heating demand, heater model

\section{Introduction}

The development of a low-carbon electricity network is constrained by the need to balance intermittent renewable supply with demand, and to maintain network stability. While additional energy storage capacity will be required, large scale storage systems are expensive. Distributing small-scale storage at the domestic level offers a cheaper option ${ }^{1}$, displacing the need for backup and improving the load factor for renewables ${ }^{2}$. Such distributed capacity exists today: electric storage heating is used in areas without mains gas and in conjunction with teleswitched, cheap off-peak tariffs that allow the utility to level demand throughout the day. Around 1.7 M households in the UK have electric storage heating and $1.3 \mathrm{M}$ have electric hot water tanks ${ }^{3}$. Together these account for $16 \%$ of domestic electricity consumption ${ }^{4}$.

Space heaters produce heat from electric resistance elements and store it in bricks of high heat capacity material covered by a layer of insulation. In sophisticated appliances, heat transfer to the room is via two modes of operation: uncontrolled natural convection from the heater surface; and controlled, fan-assisted air movement through the core ${ }^{5}$. They are inexpensive to install relative to other options, require no maintenance and deliver heat without distribution losses ${ }^{6,7}$. However, traditional models have high uncontrolled output, leading to overheating, while both input and output are difficult to control ${ }^{7}$. Hayton ${ }^{8}$ monitored space heating consumption in houses with storage heaters and found that these could provide up to $86 \%$ of the total, with the rest coming from direct heating. Room temperatures in a house with storage heaters were highest in the mornings, rather than the evening maximum observed in houses with direct heating ${ }^{9}$.

Recent research on load shifting using domestic heat storage has focused on low temperature media. Under-floor electric heating with a wax buffer layer was investigated numerically by Farid $\& \mathrm{Chen}^{10}$ and experimentally and numerically by Farid and Kong ${ }^{11}$. Lin et al $^{12}$ examined a mixed paraffin /polyethylene buffer, which keeps its form during the phase change. Qureshi et al ${ }^{13}$ built phase change materials into an office wall. Hot water buffers were investigated by Hong et al ${ }^{14}$ and Kelly et al ${ }^{15}$ to shift heat pump operation to before the morning peak load, and by Arteconi et $a l^{16}$, who switched the heat pump off during the evening peak. Studies on time shifting the charging of domestic hot water tanks have been carried out in South Africa ${ }^{17,18}$ and in Canada ${ }^{19,20}$. Finn et al $^{21}$ modelled how a price-based control system could allow excess wind to be stored in a domestic hot water tank and the impact on tank losses. 
A common finding from such studies is that the limited storage volume that can be accommodated in a normal home restricts load-shifting flexibility. The high energy storage density of traditional ceramic bricks $^{22}$, coupled with improvements in insulation and output control ${ }^{23}$, means that electric storage heaters could provide an improved solution.

A large scale trial of despatchable space and water heaters within a smart grid was implemented in Scotland's most Northerly islands. Located 160 miles from the mainland, Shetland is not connected to the UK grid so the distribution network operator, SHEPD, has to balance demand and supply across a population of just 22,000. Network stability constraints mean that only one 3.7 MW wind farm can currently be accommodated. Within their programme of work SHEPD have deployed several novel technologies that together are intended to reduce fossil fuel use, increase renewable energy generation, and improve the reliability and quality of the electricity supply ${ }^{24}$. At the system's core is an Active Network Manager (ANM), which despatches wind generators in response to demand fluctuations and controls the charging of thermal energy storage ${ }^{25}$.

Domestic space and water heaters with an electrical capacity of $2.1 \mathrm{MW}$ are distributed across 235 dwellings. The heaters, manufactured by Glen Dimplex ${ }^{26}$, receive a centrally generated charge schedule from the ANM and relay back data on thermal store status with updates every minute in both directions. The charge schedule specifies the desired input power level for each 15 minute interval in the upcoming 24 hour period based on anticipated demand, supply and network status. The charge can be varied between discrete settings. An additional feature is that the devices can respond automatically to short term changes in grid frequency, shutting down when the frequency drops below an acceptable level and increasing the charge level when frequency rises. In this way the devices support direct load shifting rather than relying on differential pricing to influence the customer's actions as in traditional demand side response $^{27}$.

This paper explores how such a controllable storage system performs under a range of approaches to charging based on field monitoring and simulation studies. Performance is assessed from the point of view of both the grid operator - controllability, storage utilisation and overall demand - and of the occupants - comfort, demand and cost.

\section{Field trials and monitoring}

Within an initial trial, a local controller in each of six monitored houses communicating with a central controller established to emulate the ANM in transmitting charging instructions and collecting status data. The six dwellings are among the lowest space heating consumers in the local social housing stock. Five were built in the late 1990s with the same insulated timber construction, while the sixth is within a 2004 development converting an old, stone-walled public building into flats. Each dwelling had two or three storage heaters with a total capacity of $4.3-6.2 \mathrm{~kW}$ : these were in the hall and living areas, with panel heaters in other rooms. All dwellings had previously had electric storage heaters, so occupants were used to the technology. Occupancy ranged from single working persons to families with two children and someone at home all day. Table 1 summarises the houses and occupancy regimes.

The space heaters were highly insulated and offered flexible control of output through a timer and a room thermostat which activated fan-assisted mode. The devices were equipped with built-in controllers which aimed to maintain occupant comfort by providing a heat reserve at all times: automatically charging when the store reached that reserve regardless of schedule. Also, in order to ensure that customers did not inadvertently run up large bills, the heaters had an adaptive control function that turned off charging beyond a point equal to the reserve plus the heater's internal estimate of the energy required for the next day. In case of conflict with the ANM instructions, the internal device controller had priority.

The trial followed the timing of the standard Shetland teleswitching schedules, allowing 8.5 hours of storage heater and 5.75 hours of hot water charging at fixed off-peak times during the day and at night. The power input level was set at maximum for the first month and then reduced to $1 / 3$ for space heaters and $30-60 \%$ for water tanks.

The monitoring scheme, as depicted in Figure 1, was designed to allow the construction of energy balances in order to determine the behaviour of the devices over time. Room temperatures and weather parameters were also recorded. Panel heater use and ventilation were not monitored due to potential occupant inconvenience.

Data was collected for 18 devices, each with 12-14 data channels, at 1-5 minute intervals. The full monitoring scheme was in operation during March-October 2012: this period included weather that was 
typical of winter conditions in Shetland. Communication problems between the local and central controllers meant that there was no single week of continuous data capture for any one heater.

Table 1: Monitored houses in the initial trial.

\begin{tabular}{cllccccc}
\hline House & Built form & Construction & Occupants & $\begin{array}{c}\text { Floor } \\
\text { area } \\
\mathbf{m}^{\mathbf{2}}\end{array}$ & $\begin{array}{c}\text { Controllable } \\
\text { input power } \\
\text { kW }\end{array}$ & $\begin{array}{c}\text { Effective } \\
\text { storage } \\
\text { kWh }\end{array}$ & $\begin{array}{c}\text { Other } \\
\text { heater } \\
\text { power kW }\end{array}$ \\
\hline $\mathbf{1}$ & Flat & $\begin{array}{l}\text { stone, retrofit } \\
\text { insulation } \\
\text { timber, well }\end{array}$ & 1 & 40 & 4.35 & 25.6 & 3.25 \\
$\mathbf{2}$ & $\begin{array}{l}\text { Semi-detached } \\
\text { house }\end{array}$ & $\begin{array}{l}\text { insulated } \\
\text { timber, well } \\
\text { insulated } \\
\text { timber, well }\end{array}$ & 4 & 95 & 6.30 & 37.1 & 4.00 \\
$\mathbf{3}$ & $\begin{array}{l}\text { Semi-detached } \\
\text { bungalow }\end{array}$ & 1 & 48 & 4.35 & 25.6 & 3.25 \\
$\mathbf{4}$ & $\begin{array}{l}\text { Flat } \\
\mathbf{5}\end{array}$ & $\begin{array}{l}\text { Semi-detached } \\
\text { timber, well } \\
\text { bungalow }\end{array}$ & 3 & 54 & 4.35 & 25.6 & 3.25 \\
$\mathbf{6}$ & Flat & $\begin{array}{l}\text { insulated } \\
\text { timber, well } \\
\text { insulated }\end{array}$ & 2 & 48 & 4.35 & 25.6 & 2.00 \\
\hline
\end{tabular}

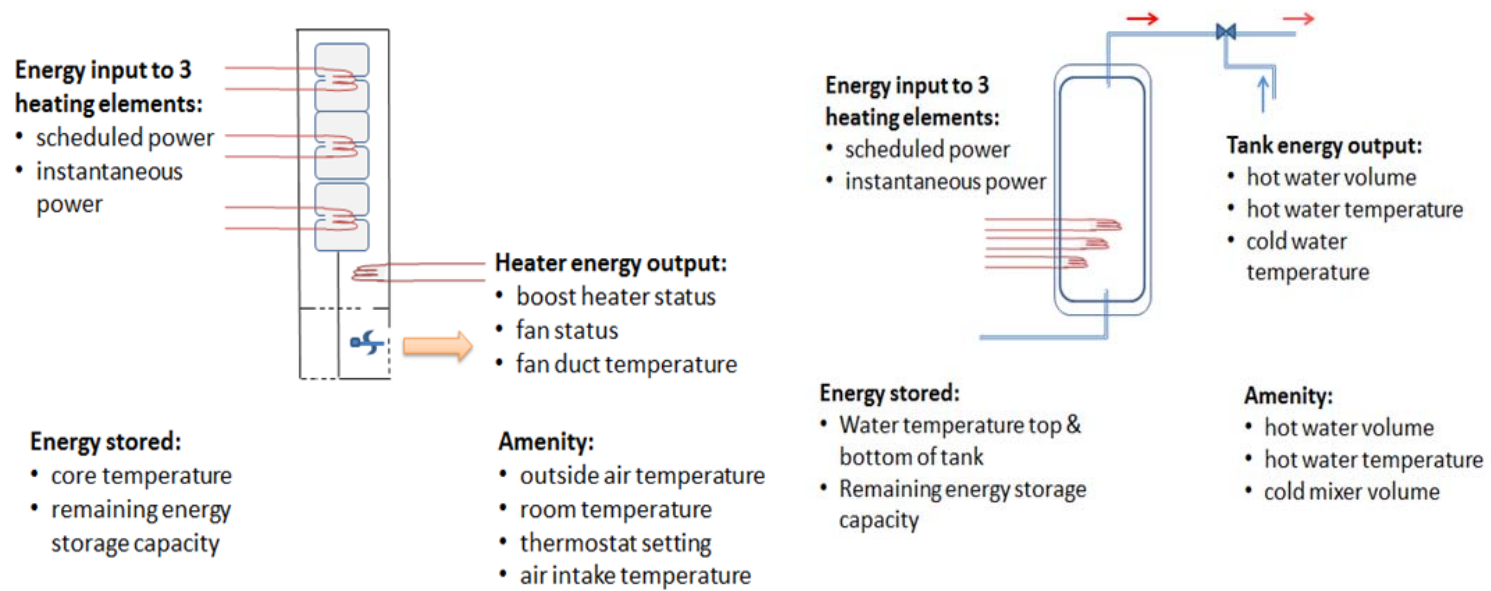

Figure 1: Space and water heater monitoring scheme.

\section{Monitoring outcomes}

A high proportion of heater charging took place outside scheduled periods for all devices. Figure 2 shows a typical pattern for the weekly power input and energy delivery to one heater. Data outages make quantitative comparisons difficult but for this heater the energy delivered outside scheduled periods was of similar magnitude to the scheduled energy not delivered.

This situation could arise for a number of reasons. When actual demand was different to that estimated by the heater controller, whether because of colder temperatures, changes in occupant behaviour, or estimation algorithm inaccuracy, the heaters would switch off when instructed to charge; and at other times charge at full capacity when not scheduled. In addition, when occupants tried to control the fanassisted heat output by turning the room thermostat settings up and down regularly rather than (as intended) setting a preferred temperature set-point via a timer, the device controllers would use an artificially low thermostat setting to calculate the next day's demand. Finally, a constant schedule was applied throughout irrespective of outside temperature or differences between the individual houses.

The stone flat (House 1) made the highest use of fan-assisted heat output, even though it had the smallest floor area and was not generally occupied during the day. However, even here, fan-assisted output was never greater than two-thirds of demand. Although the space heaters were well insulated and operating at low temperatures, they still emitted significant uncontrolled output, averaging 120-240 W or 2.9-5.8 $\mathrm{kWh}$ /day. In these dwellings this was enough to meet most of the demand except on the coldest winter 
days. Uncontrolled space heater output was not necessarily wasted heat because it did provide a level of temperature elevation that replaced the need for fan operation.

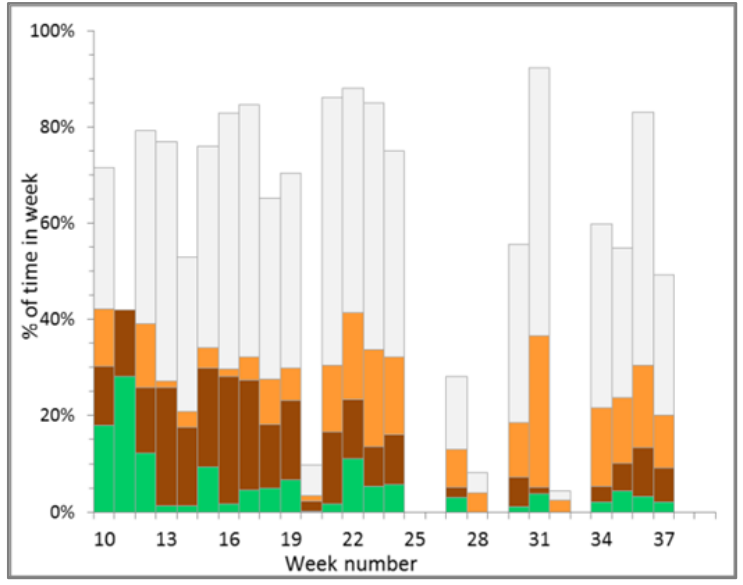

a)

Figure 2: Charging controllability for typical heater, by week: a) charging within and outside scheduled periods,

b) unscheduled energy and scheduled not delivered.

Unscheduled load drawn $\quad$ Scheduled load drawn

- Scheduled load not drawn $\quad \square$ Total data available for week

Individual heaters were rarely more than $65 \%$ full after the charging rate was reduced. Estimated demand for space heating was less than the storage capacity except for the highest demand dwelling on a severe winter day. Timing differences meant that on aggregate the 12 heaters were rarely more than $50 \%$ full (Figure 3), implying that there is excess capacity to store wind generation over more than one day. The spike at the end of March represents an update to the controller firmware. The zero readings (periods when no data was received from any heater) illustrate the extent of the outages.

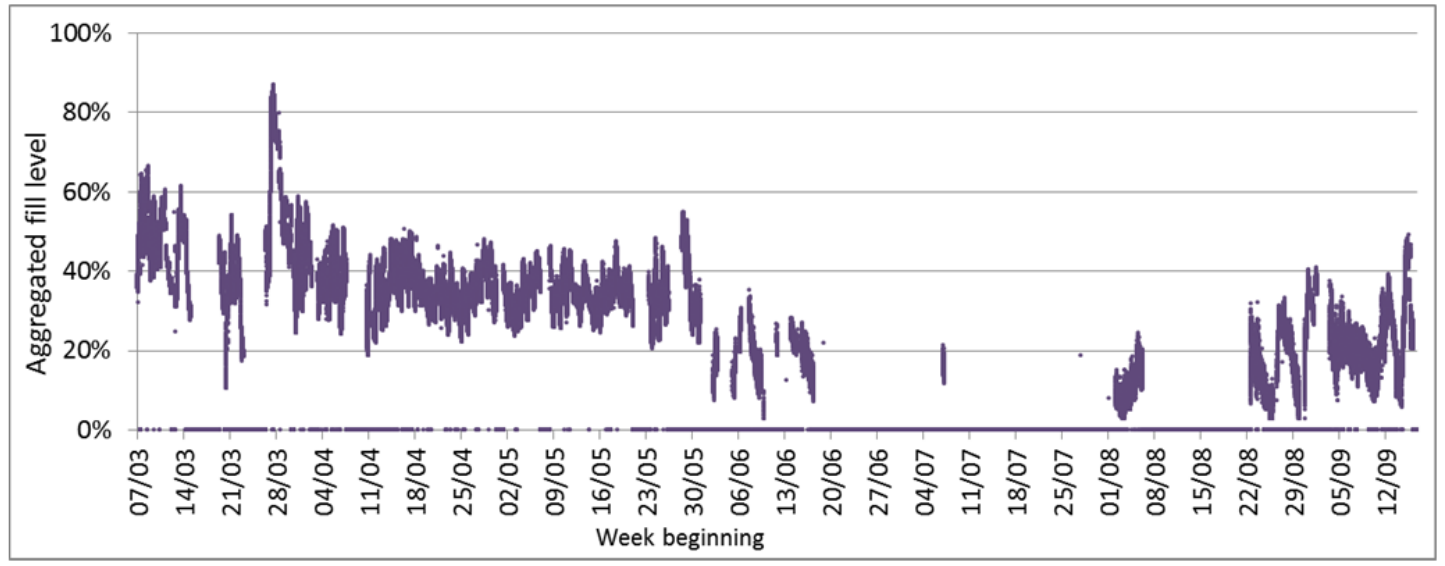

Figure 3: Storage capacity used for all space heaters.

From the occupants' point of view, the new heaters were more controllable than those they replaced. This can be seen from the convergence of the average winter living room temperatures after the upgrade: the difference between the coolest and the warmest house was $3.3^{\circ} \mathrm{C}$ rather than the $7.1^{\circ} \mathrm{C}$ with the previous equipment and charge control. The average daytime living room temperature across all houses was $20.3^{\circ} \mathrm{C}$ and there was little variation between daytime and overnight (Table 2).

The average daytime living room temperature in the trial dwellings was $0.8^{\circ} \mathrm{C}$ less than the mean recorded in 358 centrally heated houses in England and Wales ${ }^{28}$. There was also less variation between houses: in the larger survey $30 \%$ of dwellings were below $20^{\circ} \mathrm{C}$ (cool), $30 \%$ between $20-22^{\circ} \mathrm{C}$ (average), and $40 \%$ above $22^{\circ} \mathrm{C}$ (warm) during heated periods. Here only one house fell into the 'cool' category, 
with the rest average: a larger sample would be required to establish whether this is associated with storage heater use. Significantly, the house with the lowest temperature had the highest heat consumption, which might indicate that windows are regularly open when the heating is on to alleviate overheating. In contrast to experience elsewhere ${ }^{9}$, the highest temperatures were in the evening; the Shetland off-peak tariff includes 3.5 hours in the afternoon, so the heaters were not depleted by the evening.

Table 2: Living room temperatures.

\begin{tabular}{lccccccc}
\hline Living room temperatures ${ }^{\mathbf{0}} \mathbf{C}$ & House 1 & House 2 & House 3 & House 4 & House 5 & House 6 \\
\hline Daytime & $\mathbf{0 7 : 0 0 - 2 2 : 0 0}$ & 19.9 & 21.3 & 20.9 & 20.1 & 19.1 & 20.4 \\
Evening & $\mathbf{1 7 : 0 0 - 2 2 : 0 0}$ & 20.8 & 21.9 & 21.4 & 20.8 & 19.7 & 21.2 \\
Overnight & $\mathbf{2 2 : 0 0 - 0 7 : 0 0}$ & 19.6 & 21.5 & 21.1 & 19.7 & 18.5 & 21.2 \\
\hline
\end{tabular}

\section{House and heater modelling}

Models

Each trial house was modelled within the ESP-r program ${ }^{\mathrm{x}}$. Based on construction drawings, the models included detailed internal layouts to allow Quantum and panel heater outputs to be controlled separately.

Figure 4 illustrates the ESP-r model of the prototype Quantum space heaters and their deployment in one dwelling. The heater model comprised 9 thermal zones to represent the following processes:

- variable energy input to each of the three sections of the core during charging;

- heat transfer from the core to the intra-heater air stream;

- heat transfer through the insulation to the room air (uncontrolled output); and

- heat transfer from the intra-heater air stream to the room air (fan-assisted output).

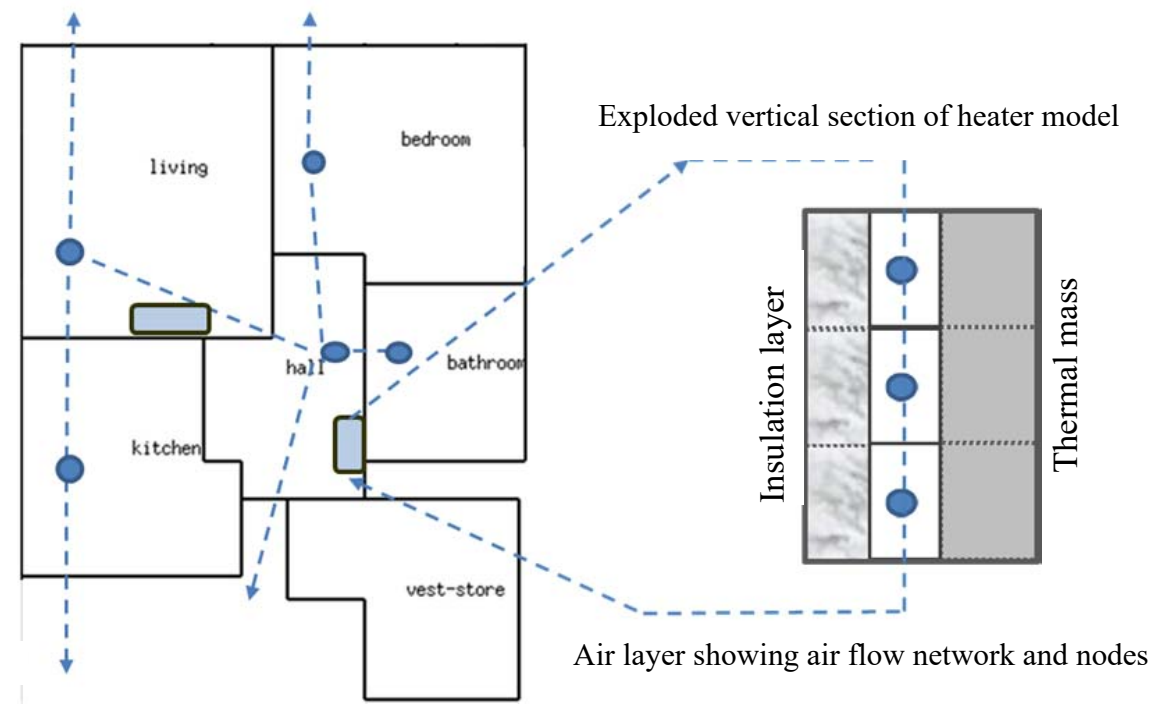

Figure 4: Simulation models for a dwelling with two Quantum space heaters.

The heater models were based on data provided by the manufacturer ${ }^{26}$. The large heater had 4 stacks of bricks sandwiching 3 x $800 \mathrm{~W}$ heating elements, while the smaller heater had 3 stacks and $650 \mathrm{~W}$ elements. Three sets of parameters were estimated from heater performance tests or from published data:

- specific heat capacity was derived from the temperature rise recorded while charging in laboratory performance tests;

- air flow rates around the brick core were estimated from heat outputs in laboratory performance tests under uncontrolled discharge and fan-assisted operation;

- dynamic convective coefficients were determined from empirical correlations corresponding to natural convection in the uncontrolled discharge case ${ }^{29}$ and forced convection when the heaters where operating in fan-assisted mode ${ }^{30}$. 


\section{Calibrations}

Figure 5 compares simulated and measured results for both laboratory and field tests. In the laboratory test, full charge was applied for 8 hours and then turned off. Temperature and power output rose rapidly and fell slowly: after 24 hours the store was still two-thirds full. Output peaked around two hours after power input stopped, as the brick temperature equalised. The simulation is close to the laboratory data, both in shape - Spearman's rank correlation coefficient of 0.99 - and magnitude - inequality coefficient of $0.02^{31}$. The corresponding agreement for power output was slightly lower but still acceptable at 0.97 and 0.03. The most significant adjustment made during calibration was in the convective heat transfer coefficient between the heater and room air.

Validation of the heater-in-house model against field data can be seen in Figure 5(b), which shows the living room temperature over 3 days. The input to the model was the measured charging profile, and the measured outside air temperature overlaid on a portion of the typical year climate file with similar wind and daylight conditions. The simulated heat output over the three days was within $15 \%$ of measured, an acceptable level of agreement given that the measured value was derived from a single temperature sensor on the outside of the bricks. Mean room temperatures agreed to within $0.1^{\circ} \mathrm{C}$. The fluctuation range was $6.3^{\circ} \mathrm{C}$ rather than the $5.1{ }^{\circ} \mathrm{C}$ measured, indicating that casual gain or ventilation behaviour was more complex than modelled. The rank correlation coefficient was 0.7 and inequality coefficient 0.03 , a moderate agreement between profile shapes and good agreement in magnitude.

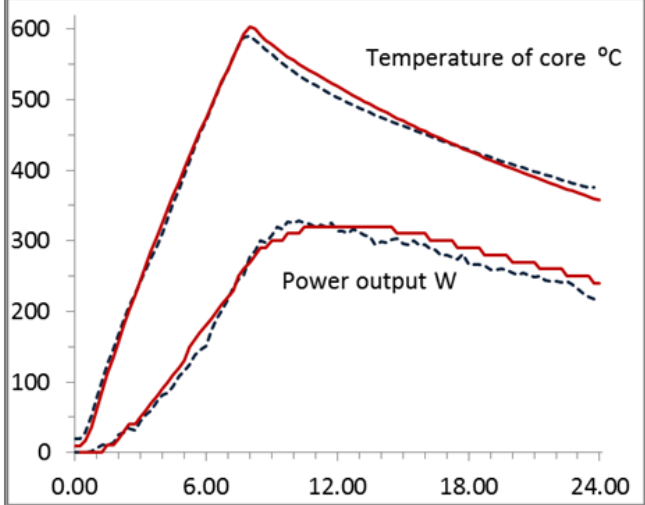

a)

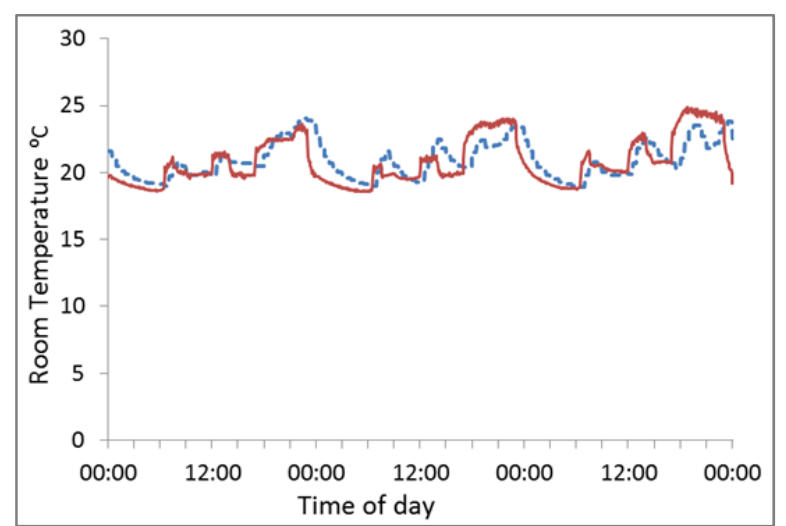

b)

Figure 5. Heater models compared to measurements: a) laboratory test data for uncontrolled output; b) field data Dotted lines represent measurements, solid lines simulations

Three significant lessons emerged from the calibration exercise as follows.

- Since the storage heaters were in effect heating the whole house, it was important to ensure that the air within the space was well mixed: an air flow network was included in the ESP-r model incorporating a kitchen extractor fan (Figure 4).

- It was necessary to run a pre-simulation period of 50 days so that the correct starting condition was reached for the heater.

- In real life the fan can switch on and off at 1-minute intervals and the simulation should ideally be run at that frequency otherwise the heat input to the room is over-estimated. However, the runs had also to cover an extended period. A time step of 5 minutes gave results within $10 \%$ of those using 1minute, so this was selected for the scheduling study in the interests of speed.

From the results it was concluded that the model offered acceptable performance for the task in hand, which was the investigation of alternative approaches to charge control.

\section{Charge control schedules}

In the field trials charging schedules were kept within the existing tariff windows, and input power at the minimum. During cold spells the heater core was not hot enough to deliver the required output and frequently hit its programmed minimum reserve level, at which point it started to charge at full power 
irrespective of instructions. When it was warm the automatic energy cap prevented full delivery of the scheduled charge. This approach therefore worked badly for both the occupants and the utility.

Simulations of alternative charging schedules were run to search for better solutions. Two of the trial houses were modelled for January-June of a typical Lerwick weather year: House 2, with low, and House 1 with high thermal mass. A simple occupancy model was applied to each - out at work or at home between 09:00 and 17.00 on weekdays - that best corresponded to the observed occupancy pattern. Casual gains and ventilation were estimated based on observations during an energy audit, and adjusted to bring the temperature range roughly in line with measurements. A first estimate of daily energy demand was made with a simplified heater model comprising a constant low power fixed output plus a thermostatcontrolled high power one, respectively equal to the uncontrolled and fan-assisted output with the heaters one-third full. Where actual daily space heating consumption could be estimated, given the intermittent nature of the data, measured consumption agreed with modelled to within $+/-25 \%$.

The estimated demand was then used to generate daily schedules. Four different approaches to energy delivery were examined:

- Teleswitching - standard condition where heaters charge at maximum during tariff hours if they physically can.

- Exact scheduling delivering the energy required each day.

- Approximate scheduling delivering the average monthly demand each day of a month - mimicking inaccurate forecasting or deliberate storage of small amounts of wind on some days.

- Flexing with wind speed - delivering up to twice the day's demand when the wind speed is high; zero or minimum needed to top up if the wind is low, taking into account the forecast fill level. This is not the same as the actual optimised schedule produced by the ANM system, but it generates a similar charging pattern.

Each approach was applied at different times of day, and at varying power levels giving 15 different schedules (Table 3 ).

Table 3. Charging regimes investigated

\begin{tabular}{cccc}
\hline Schedule & Energy delivered & Power setting & Time of day \\
\hline Te & Teleswitch, as demanded by heater & Maximum & Tariff hours \\
De & Average heater demand for month & Minimum & Tariff hours \\
Hs & Exact heater demand each day & Maximum & Early, starts 04:00 \\
En1 & Exact house demand each day & Minimum & Early, starts 04.00 \\
Ex1 & Exact house demand each day & Maximum & Early, starts 04.00 \\
Ex2 & Exact house demand each day & Maximum & Late, starts 18.30 \\
An1 & Average heater demand for month & Minimum & Early, finishes 08:00 \\
An2 & Average heater demand for month & Minimum & Late, finishes 00:00 \\
Ax1 & Average heater demand for month & Maximum & Early, finishes 08:00 \\
Ax2 & Average heater demand for month & Maximum & Night, starts 00.30 \\
Ax3 & Average heater demand for month & Maximum & Daytime, starts 14.00 \\
Ax4 & Average heater demand for month & Maximum & Late, starts 18.30 \\
Sn1 & Demand flexed with wind speed & Minimum & Early, starts 04.00 \\
Sx1 & Demand flexed with wind speed & Maximum & Early, starts 04.00 \\
Sx2 & Demand flexed with wind speed & Maximum & Late, starts 18.30 \\
\hline
\end{tabular}

The heater's internal controller could not be modelled fully as the algorithm for calculating the adaptive control cap was manufacturer's intellectual property. The cap was therefore emulated by running each schedule with 4 different maximum fill settings - unconstrained, 55\%,14\% and 4\% - representing typical caps observed in the trial.

\section{Results}

Figure 6 shows typical daily temperature profiles over 6 months in House 2. The hall is cooler than the living area not only because the set-point is lower but also because the heater is heating the first floor via the stairwell. The highest temperatures in the evening, with gains from cooking, can exceed $30^{\circ} \mathrm{C}$. The 
average living room temperature when occupied is above the set-point. A similar pattern can be seen in the high thermal mass flat, although being less insulated this does not overheat to the same extent. This profile remained almost constant for all the unconstrained active scheduling regimes in both dwellings. However, with unconstrained teleswitching, temperatures were significantly higher in both.

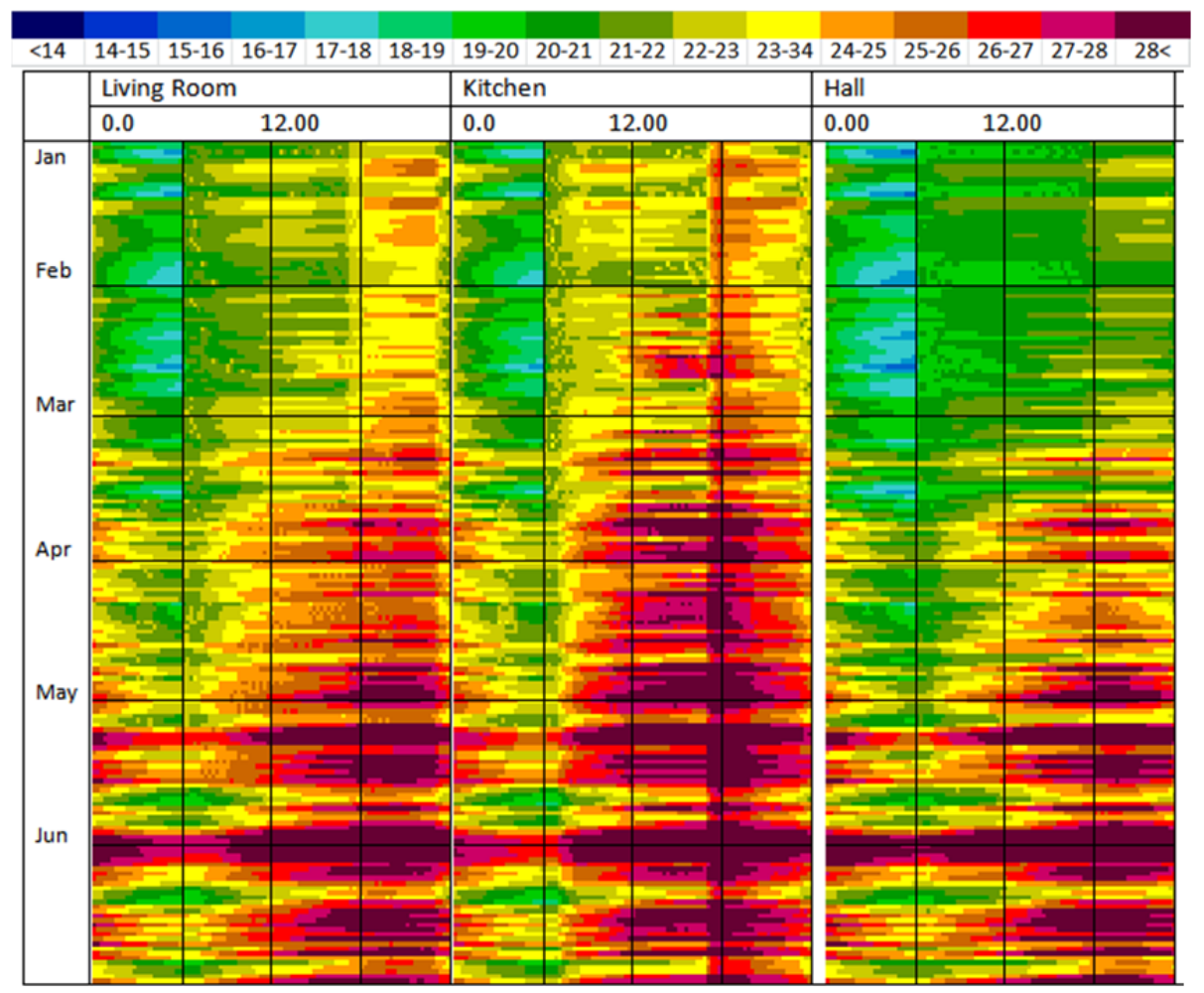

Figure 6. Room temperature variation in low thermal mass house. Scale denotes temperature in ${ }^{\circ} \mathrm{C}$.

The simulation modelled a regular daily routine, with fixed thermostat settings and ventilation rather than the real vagaries of occupant behaviour. Even so, the simulated temperature variation through the day was similar to that observed, although peak temperatures in the evenings were higher than simulated.

In May and June room temperatures exceeded $25^{\circ} \mathrm{C}$ in the evenings, even with the living room and kitchen heaters switched off. Individual occupants might react to this in a variety of unpredictable ways accepting higher temperatures, opening windows, or switching heaters off. The remaining comparisons therefore cover January to April only.

Figure 7 shows how much energy is consumed, and how well the various schedules are followed in the two houses if the fill level is unconstrained. Neither case shows a significant difference between any of the active schedules, even though House 1's specific heat demand of $115 \mathrm{kWh} / \mathrm{m}^{2} /$ year is 2.3 times that of House 2. The highest consumption in House 2 is $7 \%$ more than the lowest; in House 1, whose thick walls provide additional storage, the difference is only $2 \%$. However, with teleswitching both dwellings consume considerably more energy, $66 \%$ and $32 \%$ respectively.

For the Utility, the degree to which the schedule instructions are followed is of key importance. Schedule following is defined as

$$
\text { Schedule following index }=1-\frac{\text { unscheduled charge }+ \text { scheduled charge not drawn }}{(\text { total scheduled charge })}
$$

With active scheduling, the index ranges from $0.95-1.0$ for the stone flat and $0.81-0.95$ for the timber house. Here again, teleswitching gives dramatically worse performance.

Timing and power input level have a small secondary effect. Delivering energy at high power over a shorter time results in $2-3 \%$ higher unscheduled consumption than the same amount scheduled at low power over an extended period. Scheduling late in the day - afternoon or early overnight - consistently gives rise to unscheduled demand in the mornings. 


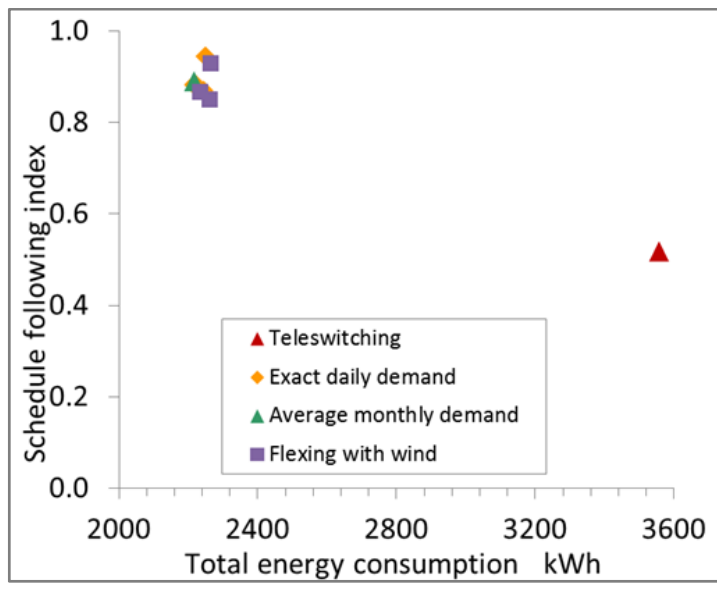

a)

Figure 7. Heat consumption and schedule following with different charging regimes: a) timber house (House 2), b) stone flat (House 1).

The effect of capping the heater fill level can be seen in Figure 8. Note the scale of the axes: the small dotted boxes represent the total range covered in Figure 7 . In all cases, total consumption reduces as maximum fill level is decreased; however, the proportion that is uncontrollable grows, dramatically so when the cap is low. This replicates the observed situation with high unscheduled charging if the cap is applied. Room temperatures are on average $1^{\circ} \mathrm{C}$ lower when fill level is constrained to $14 \%$ or lower.

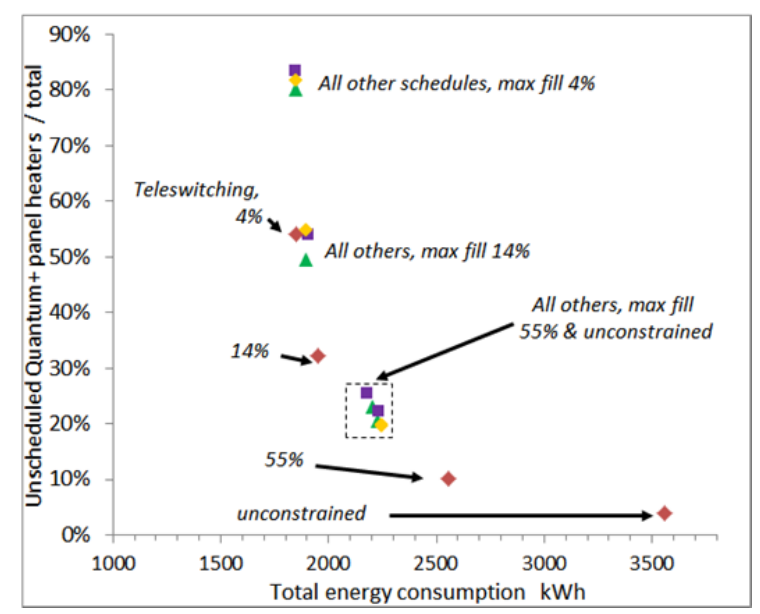

a)

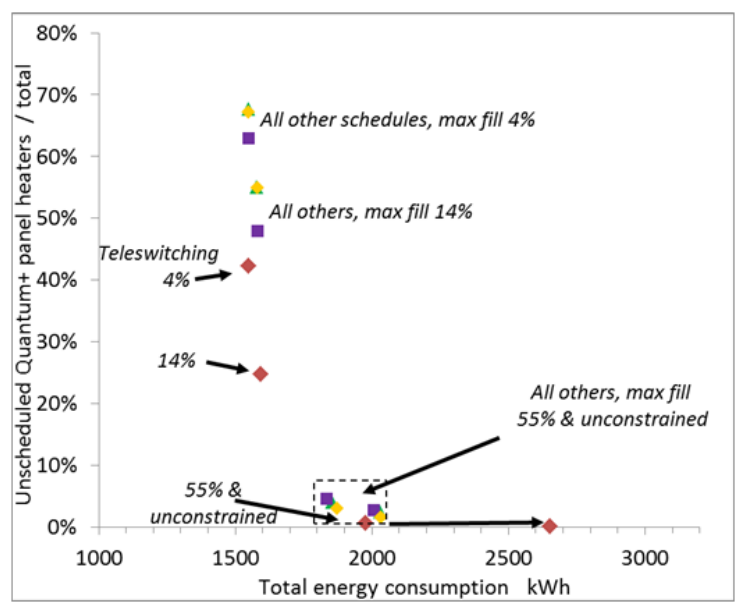

b)

Figure 8. Uncontrollable and total heat consumption with different levels of storage cap: a) timber house (House 2), b) stone flat (House 1)

With unconstrained or 55\% fill, the stone flat required almost no direct heating due to its compact layout and the effective storage capacity increase from the walls. The better insulated house used more direct heating as the relatively small hall heater was pumping heat to the entire upper floor, while the living room and kitchen were over-heated through having two heaters in a relatively small area. Teleswitching is essentially demand driven, so there is less unscheduled charging and use of panel heaters, even at lower cap levels.

Figure 9 shows storage capacity utilisation for the two houses under various unconstrained charging regimes. Scheduling over more than one day increases capacity utilisation at the cost of around only $1 \%$ more consumption than the equivalent charging regime delivering exactly the day's forecast. In House 2 the storage capacity is 2.2 times the average daily demand, while House 1 with a capacity of 1.5 times demand has less headroom. The fact that the heaters never actually reach $100 \%$ capacity utilisation illustrates the limitations of this kind of static scheduling. 


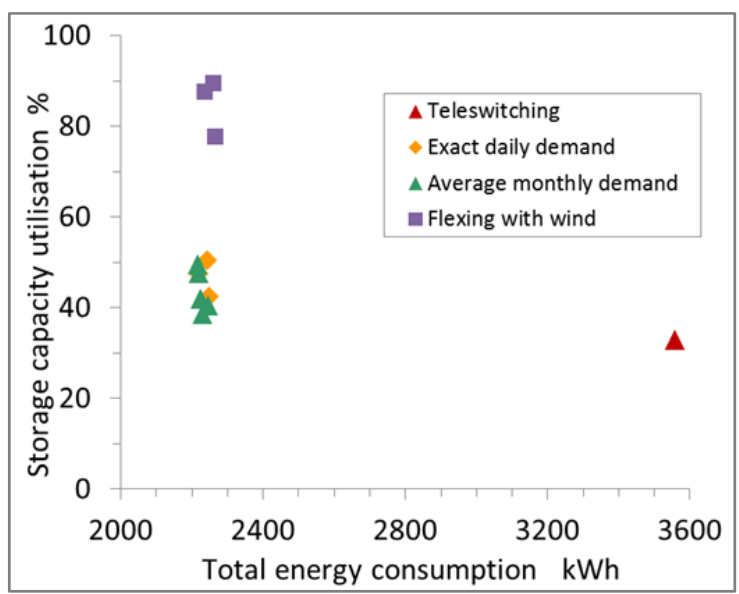

a)

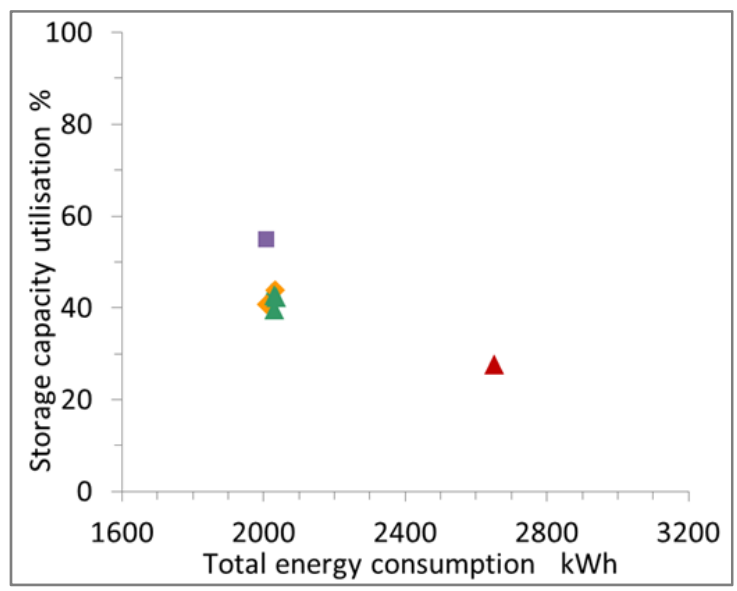

b)

Figure 9. Storage capacity utilisation: a) timber house (House 2), b) stone flat (House 1).

The benefits from improving heater insulation were investigated by setting the air flow rate to reduce uncontrolled output to $50 \%, 10 \%$ and $0 \%$ of the original level for House 2 . Halving the losses reduces energy use by about $6 \%$ and increases capacity utilisation, without reducing schedule following or room temperatures significantly. However, cutting to $10 \%$ or eliminating losses entirely results in $0.5-1.0^{\circ} \mathrm{C}$ lower room temperatures and increasing reliance on panel heaters.

Finally, a similar set of schedules was applied to a model of a poorly insulated bungalow with timber frame and block walls, typical of older dwellings in Scotland. Heaters performed much as before: maximum 3\% difference in total energy consumption, and a schedule following index between $0.85-0.9$ across all the active schedules applied. However, with a specific heat demand around double that of House 1, the four storage heaters struggled to maintain set-point temperatures in January and February even though they drew 5\% more energy than scheduled. There was also less headroom for storing excess wind as the baseline storage capacity utilisation was over $75 \%$.

\section{Discussion}

For the network operator, this is demonstrably a better technology than teleswitched storage heating. Schedule following is higher, and total demand lower, provided the scheduled energy delivery was roughly in line with demand. Small consistent differences in detail do appear: it is slightly better to charge early in the day, and at low rather than high power level. Scheduling in the afternoon or early overnight causes some unscheduled load shortly after the heating comes on in the morning: this could be compensated by slightly higher total delivery, although this aspect has not been investigated.

The new technology also benefits occupants: the heaters are more controllable, so use less electricity and cause less overheating than before. Occupants should see only minimal differences in room temperature, energy used or costs with different charging schedules, again provided charge is roughly in balance with demand. This applies even when double the demand is delivered on some days, none on others, and is not influenced by house construction. However, for a given thermostat setting room temperatures will be above set-point in well-insulated dwellings and lower in poorly insulated ones whatever the schedule. Simulation also highlighted a counter-intuitive feature of heater control: since both fan-assisted and uncontrolled output depend on the level of fill, turning up the thermostat can lead to a downward spiral where the fan switches on more often, lowering the core temperature and reducing the heat output, which then requires even more use of the fan. Eventually this has to be compensated for with costly direct heating.

Benefits to both Utility and occupant can however be wiped out if the device's adaptive control cap is operational. The device and central controllers compete with each other, with the net effect of pushing demand from scheduled to unscheduled periods and from storage to direct heating, increasing costs for customer and peak load for utility. However, the simulations did demonstrate the efficacy of the device cap in reducing energy consumption and regulating temperature with teleswitching where the heater would otherwise fill to maximum at every opportunity. 
Storage heaters use more energy than direct heating because the uncontrolled output is continuous. If heat output between midnight and 6 a.m. is considered mostly unnecessary, the best insulated house studied consumed $25 \%$ more electricity than needed, and the worst insulated $14 \%$. This is the same or less than the energy penalty reported when using a hot water buffer to shift heat pump operation: $16 \%$ where it is shifted outside a 3 -hour early evening peak ${ }^{16}$ and over $60 \%$ if the pump operates under standard Economy 10 timing $^{15}$. But storage heaters allow much greater flexibility in timing.

The heater storage capacity would allow scheduling over 48 rather than just 24 hours. In all three houses studied it was possible to do this without increasing indoor temperatures and only a small penalty in the demand. Future improvements in heater insulation that reduce uncontrolled output by $50 \%$ would reduce even that penalty.

In order to work reliably the ANM scheduling system needs a reasonably accurate demand forecast for the storage heaters. Their contribution to total consumption depends on how many and where they are in a given building layout, as well as on the normal complexities of house size, construction, thermal mass, occupant behaviour and weather conditions - this was also noted elsewhere ${ }^{8}$. Such forecasts can best be made through dynamic simulation.

A practical pre-requite is robust communications technology. In its first field trial the new system was set for a full data exchange between centre and houses every minute, and this may have contributed to the communications outages and loss of central control. Since the schedule is in 15 minute blocks, data exchange at 5 or 10 minute intervals would place less onerous demand on communications without compromising functionality.

How could this technology benefit the mainland grid? Simulations of the whole NINES network with about $20 \%$ of all households equipped with smart heaters identified three possibilities ${ }^{32}$. The increased load factor that allowed an additional $15 \mathrm{MW}$ of wind to be operated economically, and the 2.9-4.2 $\mathrm{GWh}$ year reduction in fossil fuels with corresponding $\mathrm{CO}_{2}$ emissions, would clearly be directly transferrable. The third area is a peak load reduction of $2 \mathrm{~kW} /$ house. Shetland, where $50 \%$ of households are on some form of restricted tariff, is a case study of what happens when electric heating becomes widespread. A technology that permits controllable load shifting over 6 hours or more would be economically advantageous ${ }^{2}$.

\section{Conclusions}

Field trials and simulations of remotely controllable space heaters operating as distributed energy storage within a smart grid demonstrate that this technology would work well for both the Utility and the customer. The former can schedule charging flexibly over 48 hours, with little impact on total demand and high confidence that the schedule will be followed. The occupants should see lower costs, and less overheating. Pre-requisites are communication technology that is robust and reliable, and a reasonable daily demand forecast for each house.

\section{Acknowledgements}

This project was undertaken with funding from SHEPD. The authors also acknowledge the assistance of Glen Dimplex and Hjaltland Housing Association in providing information.

\section{References}

1 Foote CET, Roscoe AJ, Currie RAF, Ault GF, and McDonald JR. Ubiquitous Energy Storage. Proc Int Conf. Future Power Systems, Amsterdam, November 2005

2 Strbac G, Aunedi M, Pudjianto D,Djapic P, Teng F, Sturt A, Jackravut D, Sansom R, Yufit V, Brandon N. Strategic assessment of the role and value of energy storage systems in the UK Low Carbon Energy Future. Report for Carbon Trust, June 2012

3 Dept. Energy \& Climate Change. Energy consumption in the UK, Domestic Data Tables t, o 2012, https://www.gov.uk/government/publications/energy-consumption-in-the-uk (viewed 25 July 2013)

4 Digest of UK energy statistics (DUKES) Chapter 1 Energy. Energy consumption by final user (energy supplied basis), 1970 to 2012 https:/www.gov.uk/government/publications/energy-chapter-1-digest-ofunited-kingdom-energy-statistics-dukes (viewed 25 July 2013) 
5 Hasnain SM. Review on sustainable thermal energy storage technologies. Part I heat storage materials and techniques. Energy Conv \& Mgmt 1990; 30:1127-1138

6 Oughton D R, Hodkinson S and Faber O. Electrical storage heating in: Faber \& Kell's Heating \& Airconditioning of Buildings $10^{\text {th }}$ ed, Taylor \& Francis 2008

7 Which? Reviews: Home heating systems: Electric central heating pros and cons http://www.which.co.uk/energy/creating-an-energy-saving-home/guides/home-heating-systems/electriccentral-heating/, accessed 13 November 2013

8 Hayton J. Heating consumption measurement in electrically heaterd dwellings. Building Serv. Eng. Res. Technol. 1994; 15:19-24

9 Yohanis YG, Mondol JD Annual variations of temperature in a sample of UK dwellings. Applied energy 2010; 87: 681-690

10 Farid MM, Chen XD. Domestic electrical space heating with heat storage. Proc IMechE Part A: J Power and Energy; 1999; 213:83-92

11 Farid M, Kong WJ. Underfloor heating with latent heat storage. Proc IMechE Part A: J Power and Energy; 215: 601-609

12 Lin K, Zhang Y, Xu X, Di H, Yang R, Qin P. Exeprimental study of under-floor electric heatng system with shape-stabilised PCM plates. Energy and Buildings 2005; 37:215-220

13 Qureshi WA, Nair NKC, Farid MM. Impact of energy storage in buildings on electricity demand side management. Energy Conv \& Mgmt 2011; 52: 2110-2120

14 Hong J, Kelly NJ, Richardson I and Thomson M. Assessing heat pumps as flexible load. Proc IMechE Part A: J Power and Energy 2013 227:30-42

15 Kelly NJ, Tuohy PG, Hawkes A. Perfromance assessment of buffered heat pump load shifting in dwellings. Applied Thermal Engineering submitted July 2013 CHECK AT END

16 Arteconi A, Hewitt NJ, Polonara F. Domestic demand-side management (DSM): Role of heat pumps and thermal energy storage (TES) systems Applied Thermal Engineering 2013; 51:155-165

17 Lane IE. A model of the domestic hot water load. IEEE Trans. Power Systems 1996; 11:1850-1855

18 Rankin, R Rousseau PG. Demand side management in South Africa at industrial residence water heating systems using in-line water heating technology. Energy Conv \& Mgmt 2008; 49: 62-74

19 Lacroix M. Electric water heater designs for load shifting and control for bacterial contamination. Energy Conv \& Mgmt 1999; 40:1313-1340

20 Moreau A. Control strategy for domestic water heaters during peak periods and its impact on the demand for electricity Energy Procedia 2011; 12:1074-1082

21 Finn P, Fitzpatrick C, Connolly D, Leahy M; Relihan L. Facilitation of renewable electricity using price based appliance control in ireland's electricity market. Energy 36:2952-2960

22 Otero de la Gandara JL and Alvarez P. Use of magnetite in the production of bricks for heat accumulation, Rev. Metal. Madrid, 1994; 3:135-144

23 Glen Dimplex The Quantum Energy System http:/www.quantumheating.co.uk/the-systemexplained.php (viewed 10/08/13)

24 SHEPD. Proposals for the development of the integrated plan for Shetland (2011) Ofgem Online, www.ofgem.gov.uk/Networks/ElecDist/Policy/Documents 1/Phase\%201\%20Consultation\%20Aug\%2020 11.pdf (viewed 12/02/12)

25 Gill S, Ault G, Kockar I, Foote C and Reid S. Operating a wind farm in the future smart grid - lessons from designing and deploying a smart grid on Shetland. in: European Wind Energy Conference, Copenhagen, February 2013

26 Glen Dimplex. Energy store room heater technical Specification, 17 February 2011

27 Ofgem. Demand side response, Office of Gas and Electricity Markets, 15 June 2010 www.ofgem.gov.uk/Sustainability/Documents1/DSR\%20150710.pdf (viewed 15/03/13).

28 Shipworth M, Firth S K, Gentry M I, Wright A J, Shipworth D T and Lomas K J. Central heating thermostat settings and timing: building demographics', Building Research \& Information; 2012; 38(1):50-69

29 Alamdari F, Hammond GP and Melo C. Appropriate calculation methods for convective heat transfer from building surfaces', Proc. $1^{\text {st }}$ UK National Conf. on Heat Transfer; 1984; 2:1201-1211

30 Fisher DE and Pederson CO. Convective heat transfer in building energy and thermal load calculations, ASHRAE Transactions; 1997; 103(2):137-48 
31 Born FJ, Clarke JA, Johnstone CM. Development and demonstration of a renewable energy based energy demand/supply decision support tool for the building design profession. Proc 7th IBPSA Conference, Rio de Janeiro, Brazil 2001 245-250

32 Gill S, Kockar I: Unit scheduling simulations report in support of Shetland repowering, University of Strathclyde, April 2013 